\title{
The Distrusted Truth: Examination of Challenged Perceptions and Expectations
}

\author{
Eitan Elaad \\ Ariel University, Ariel, Israel \\ Email: elaad@netvision.net.il \\ Received 25 February 2015; accepted 3 April 2015; published 9 April 2015 \\ Copyright (C) 2015 by author and Scientific Research Publishing Inc. \\ This work is licensed under the Creative Commons Attribution International License (CC BY). \\ http://creativecommons.org/licenses/by/4.0/

(c) (i) Open Access

\begin{abstract}
Three experiments were designed to investigate various aspects of the distrusted truth. In the first experiment, 60 undergraduate students were asked to self-assess their abilities to tell and detect lies, tell truths and trust others. The truth-telling ability was self-assessed higher than all four abilities. Participants further evaluated the importance of the four abilities. The ability to tell the truth convincingly was evaluated as very important. In the second experiment 80 undergraduate students reported that their feelings would be severely hurt if other people question their truthful messages. The third experiment put these attitudes to a test when 60 undergraduate students took part in a truth telling task in which the four judges presumed deception. After each session participants received either a confirming feedback indicating that they were convincing when they told the truth, a challenging feedback indicating that they failed to convince, or no feedback. It turned out that feedback did not affect participants' subsequent self-assessed truth telling ability. However, predicted success in delivering convincing truths declined when the challenging feedback was introduced. Results were discussed with reference to situations where the perceived ability to tell the truth convincingly may be challenged.
\end{abstract}

\section{Keywords}

Telling the Truth, Deception, Trust, Hurt Feelings, Interrogation

\section{Introduction}

People are confident of their ability to convince receivers of their truthful communication (Elaad, 2009, 2011). This rest on the belief that truth-telling is a simple matter of "telling it like it is" (Buller \& Burgoon, 1996; Miller \& Stiff, 1993). Furthermore, such confidence goes well with general human assumptions that most communications are truthful and there is no reason to doubt truthful communications. DePaulo and her colleagues (2003) 
argued that truth-telling may occasionally be challenged (e.g., when the truth may offend or insult another person). They also contended that telling the truth is more than a mere presentation of reality: there are different ways to tell the truth, and some are very complicated. On the other hand, lies may be easily formulated when they are based on scripts of familiar stories. Nonetheless, DePaulo and her colleagues (2003) admitted that examples of difficult lies and simple truths are more available than easily formulated lies or hard-to-tell truths.

The ability to deliver the truth convincingly is especially important in the interrogation situation. Recent admissibility of DNA evidence in court has led to the exoneration of innocent individuals who were convicted after confessing to a crime they never committed. It has been reported that false confessions and admissions are present in roughly 25\% of all DNA exonerations (Kassin, Bogart, \& Kerner, 2012). In all these cases suspects failed to convince that they were truthful.

People fear being disbelieved (Bond \& DePaulo, 2006). Prevailing logic implies that honest people always act honestly and when a statement is labeled a lie, the person who made the statement is considered a liar. To call someone a liar is a serious accusation, and being considered a liar is extremely undesirable. Furthermore, people are proud of speaking the truth and sometimes people even volunteer truthful communications that oppose their own interest. Keeping all this in mind, truth tellers are anxious to be believed.

The state of mind of the distrusted truthful person warrants further examination. The self-assessed ability to tell the truth convincingly, the hurt feelings that are involved when the truth is not believed, and the actual failure to convince when telling the truth are the focus of the present study.

\section{Experiment 1: Lie and Truth Telling, Lie Detection and Trusting Abilities and Their Evaluated Importance}

Research on the perceived ability to tell and detect lies, tell truths and trust others indicated that people tend to overestimate their own ability to tell the truth convincingly. This was reported among police investigators (Elaad, 2009), prisoners (Elaad, 2009), adolescents (Elaad et al., 2012), students (Elaad, 2011), and laypersons (Elaad, 2009). The bias can be explained by the "illusion of transparency" (Gilovich, Savitsky, \& Medvec, 1998) which suggests that in communications, senders are anchored to their own internal experience. Although they realize that recipients are not exposed to the same information as they are their adjustment is insufficient (Tversky \& Kahneman, 1974), and they still tend to believe that the receiver has the ability to discern their internal states and find out that they are telling the truth. Another explanation corresponds to peoples' desire to sustain a positive self-image (Kaplar \& Gordon, 2004). The ability to tell the truth convincingly is a desirable disposition.

People also tend to overestimate their ability to detect lies (e.g., Ekman \& O'Sullivan, 1991; Elaad, 2003). Such an overestimation was reported among law-enforcement officers in general (Elaad, 2003), and police investigators in particular (Elaad, 2009), among prisoners and laypersons (Elaad, 2009), and among adolescents (Elaad et al., 2012). In contrast, no lie-detection bias was reported among some groups of students (e.g., Elaad, 2011). The last result can be explained by the notion that lie-detection accuracy of young students is poorer than that of adults (cited in O'Sullivan, et al., 2009).

The lie-detection bias can be explained by the prevailing norms that dictate people not allow themselves to be easily deceived (Don't be a sucker). In support of this attitude people would like to see among their traits the ability to detect lies. Therefore, they evaluate themselves as better lie catchers than others.

The lie-telling bias or the underestimated ability to tell lies convincingly (Ekman \& O'Sullivan, 1991; Elaad, 2003, 2011; Vrij, 2008) was observed among students (Elaad, 2011), prisoners (Elaad, 2009), laypersons (Elaad, 2009), adolescents (Elaad et al., 2012), and among law enforcement personnel (Elaad, 2003). However, a group of police investigators tended to rate their lie-telling abilities higher than others (Elaad, 2009). The underestimated lie-telling ability can also be explained by the illusion of transparency (Gilovich et al., 1998). As peoples' adjustment is insufficient they fear that the receiver has the ability to absorb their feelings and thoughts and detect their lies. The desire to sustain a positive self-image also contributes to the lie-telling bias. Thus, if I am not an able lie-teller I am entitled to believe that I am an honest person.

In all these studies participants were asked to compare their abilities with other people's abilities. The following question is would the same results hold when participants rate their lie and truth related abilities with no reference to other people? This question will be examined in the first study. Furthermore, the importance people attribute to their abilities to tell and detect lies tell truths and trust others may explain their ratings. It is hypothesized that the truth-telling ability which is expected to be rated higher than the other abilities would be judged as 
the most important ability. This hypothesis will also be examined.

\subsection{Method}

\subsubsection{Participants}

Participants were 60 undergraduate students ( 5 males and 55 females) with a mean age of 22.7 years, (SD = 1.54), who agreed to take part in the study. Participants were entitled to course credit for their participation. They completed the questionnaire individually and were assured of confidentiality and anonymity.

\subsubsection{Materials and Procedure}

Participants were first asked to self-assess their own lie-detection, lie-telling, truth-telling and trusting abilities. Answers ranged from 0 (very poor) to 100 (very good) with 50 (nor good nor bad) serving as the middle point. Participants were asked, for example, "How would you assess your own ability to tell the truth convincingly?"

Participants were further asked to complete another questionnaire consisting of four items on which they assessed the importance to: convince other people in the truthfulness of their lies, be able to detect lies in others, to deliver their truths convincingly, and to trust other peoples' truthful communication. Answers ranged from 0 (not at all important) to 100 (extremely important). A middle point (50) was defined as: "nor important nor unimportant".

\subsection{Results}

Assuming that the middle point (50) "nor good nor bad” represents the expected median rating, an unbiased selfassessment should be evenly distributed above and below the median. It emerged, however, that very often participants self-assessed their truth-telling ability above the middle point (57 of 60 participants). The above/below frequency difference is significant $\left(\chi_{(1)}^{2}=48.6, p<.001\right)$. Similar results were obtained for the ability to trust others (51 of 60) $\left(\chi_{(1)}^{2}=29.4, p<.001\right)$, and for the lie-detection ability (39 of 60) $\left(\chi_{(1)}^{2}=5.4, p=.02\right)$. The lie-telling ability showed no significant above/below frequency difference $(36$ of 60$)\left(\chi_{(1)}^{2}=2.4, p=.12\right)$. It may be concluded that students tend to assess high their truth-telling and their trusting abilities. The lie-telling ability is not evaluated high very often.

Another way to describe theses result is by comparing the mean ability assessments obtained for the student sample (Table 1). A 2 Communication (to tell vs. to detect) $\times 2$ Sincerity (lies vs. truths) ANOVA was conducted on the self-assessed ability scores with both factors serving as within-participants factors. A significant, $F_{(1,59)}=44.4, p<.001, \eta_{p}^{2}=.43$, Sincerity effect was obtained, indicating that participants self-assessed their truth-related abilities (tell truths and trust others) higher than their lie-related abilities. No significant main effect for Communication was obtained $\left(F_{(1,59)}=0.5, n s\right.$.). A significant Sincerity $\times$ Communication interaction effect, $F_{(1,59)}=5.0, p=.029, \eta_{p}^{2}=.08$, implies that while the ability to deliver truths convincingly is rated the highest the ability to deliver lies convincingly is rated the lowest. Using a t-test for paired samples reveal a significant difference, $\mathrm{t}_{(59)}=6.6, p<.001$.

As to the importance ratings, they were also compared to the middle point (50). It emerged, that very often participants rated high their truth-telling importance (54 of 60). No wonder that the frequencies above/below the middle point are significantly different $\left(\chi_{(1)}^{2}=38.4, p<.001\right)$. Similar results were obtained for the ability to trust others (58 of 60) $\left(\chi_{(1)}^{2}=52.3, p<.001\right)$, and for the lie-detection ability (54 of 60) $\left(\chi_{(1)}^{2}=38.4, p<.001\right)$. Again, the lie-telling ability showed no significant above/below difference (27 of 60$)\left(\chi_{(1)}^{2}=0.6, p=.44\right)$. In summery students assigned importance to their abilities to tell the truth, trust others and detect lies in others, but not to their ability to tell convincing lies.

Mean importance ratings are displayed in Table 2. A similar $2 \times 2$ (Sincerity, Communication) ANOVA, with

Table 1. Percent means (and SDs) of self-assessed abilities to tell and detect lies, tell truths and trust others.

\begin{tabular}{ccccccccccc}
\hline & Detect Lies & Tell Lies & Trust others & Tell Truths & Truths & Lies & Detect & Tell & Total \\
\hline Mean & .63 & .58 & .78 & .82 & .80 & .60 & .70 & .70 & .70 \\
SD & .22 & .28 & .16 & .14 & .11 & .21 & .14 & .17 & .12 \\
\hline
\end{tabular}

Truths $=($ Trust + Tell truth $) / 2 ;$ Lies $=($ Detect lies + Tell lies $) / 2 ;$ Detect $=($ Trust + Detect lies $) / 2 ;$ Tell $=($ Tell lies + Tell truth $) / 2 ;$ Total $=($ Trust + Tell truth + Detect lies + Tell lies)/4. 
Table 2. Percent means (and SDs) of the evaluated importance to convincingly tell and correctly detect lies, tell truths and trust others.

\begin{tabular}{ccccccccccc}
\hline & Detect Lie & Tell Lie & Trust Others & Tell Truth & Truths & Lies & Detect & Tell & Total \\
\hline Mean & .79 & .48 & .86 & .83 & .84 & .63 & .83 & .65 & .74 \\
SD & .22 & .29 & .13 & .18 & .12 & .19 & .14 & .17 & .12 \\
\hline
\end{tabular}

Note: Higher scores indicate higher ratings of importance.

repeated measures for the two factors, was conducted on the importance ratings. A significant, $F_{(1,59)}=53.6, p$ $<.001, \eta_{p}^{2}=.48$, Sincerity effect indicates that truth-related abilities were considered more important than lierelated abilities. A significant, $F_{(1,59)}=43.1, p<.001, \eta_{p}^{2}=.42$, Communication effect implies that the detecting abilities were perceived to be more important than the telling abilities (due to the extremely low importance assigned to the ability to tell lies convincingly). Finally, a significant, $F_{(1,59)}=30.1, p<.001, \quad \eta_{p}^{2}=.34$, Sincerity $\times$ Communication interaction effect was revealed. The interaction re-emphasized the low importance of the lie telling ability in relation with all other abilities.

It seems that the correlation between perceived lie-truth ability scores and their assigned importance is meaningful. It turned out that the low ability to tell-lies convincingly was significantly correlated with the low importance to tell convincing lies $\left(\mathrm{r}_{(1,60)}=.31, p=.016\right)$. Similar significant correlations were computed for the liedetecting ability $\left(\mathrm{r}_{(1,60)}=.31, p=.017\right)$, the truth-telling ability $\left(\mathrm{r}_{(1,60)}=.26, p=.044\right)$ and trusting $\left(\mathrm{r}_{(1,60)}=.33, p\right.$ $=.009)$.

\subsection{Discussion}

The ability scores that were assessed were higher than those reported in previous studies (e.g., Elaad, 2009, 2011) mainly because this time no reference to other peoples' abilities was made. However, the direction and the relative strengths of the various abilities stay intact. Specifically, truth-related abilities were assessed higher than lierelated abilities.

The strong link between the self-assessed abilities and their perceived importance may suggest that ability ratings can be explained by their importance. For example, the high rating of the truth-telling ability can be explained by the importance people attribute to convincing other people by their truths. In contrast, the lie-telling ability received lower ratings because it is less important to be a good liar than to be a convincing truth teller. This "importance bias" suggests that: "it is important to possess a specific trait therefore I believe I have it". The opposite is also true and ability may influence importance. Thus, "I believe I possess the ability, therefore it is important to have it".

The present experiment can be criticized for using an unbalanced sample of participants where most of the participants were females. Possible gender differences in the ability ratings may have affected the results. Therefore, caution is recommended when discussing them.

The next question is what happens when the delivered truth fails to convince? It is expected that strong hurt feeling would be involved. When the communication is less appreciated (e.g., lie-telling) the failure to convince involves more moderate feelings. The following experiment was designed to examine these predictions.

\section{Experiment 2: Hurt Feelings When Lies and Truths Fail to Convince}

The main purpose of Experiment 2 was to examine the extent to which hurt feelings are involved when appreciated and less appreciated lie-truth communications fail to convince. Specifically, it was hypothesized that when an appreciated ability, such as to tell the truth convincingly, fails to convince, strong hurt feelings would be shown. A failure of a less appreciated communication skill (telling-lies) will be associated with weak hurt feelings. To test the hypothesis under more balanced conditions than in Experiment 1 an equal number of male and female participants were selected.

\subsection{Method}

\subsubsection{Participants}

Participants were 40 male and 40 female undergraduate students (mean age $=25.8$, years, $\mathrm{SD}=4.0$ ). Partici- 
pants volunteered to complete a questionnaire about truth and deception. Participants completed the questionnaire individually after they were assured of their anonymity.

\subsubsection{Procedure}

Participants were asked to indicate the extent to which they would feel hurt (a) when they fail to convince others of their own lies; (b) when they fail to detect others' lies; (c) when they fail to trust others' truths; (d) when they fail to convince others of their own truths. Participants reported their evaluations on a scale ranging from 0 (not at all) to 100 (very much), with 25 (little), 50 (to some extent), 75 (much) serving as anchors. One half of the participants in each gender group received the questions in the described order and the other half received the questions in the reverse order.

\subsection{Results}

The differences in the mean ratings of hurt feelings caused by various lie/truth communications appear in Table 3. In order to test the hypothesis that it would hurt more when truth related communications fail to convince than when lie-related communications proved unsuccessful, a $2 \times 2 \times 2$ ANOVA with two within-participant factors: Sincerity (lies, truths), Communication (to tell, to detect), and one between-participant factor: Gender (male, female), was conducted on the mean hurt feelings ratings. A significant, $F_{(1,78)}=59.9, p<.001, \eta_{p}^{2}=.43$, main effect for Sincerity shows that the participants expected to feel more hurt when truths rather than lies failed to convince. A significant, $F_{(1,78)}=14.9, p<.001, \eta_{p}^{2}=.16$, main effect for Communication shows that participants reported that they expected more hurt feelings when they failed to convince others, and less hurt feelings when they failed to detect deception or failed to trust others. A significant, $F_{(1,78)}=64.8, p<.001, \eta_{p}^{2}=.45$, Sincerity $\times$ Communication interaction further shows that participants expected hurt feelings to be strongest when they fail to deliver their truth convincingly and their hurt feelings to be weakest when their lies failed to convince. No significant results were obtained for gender effects, indicating that male and female students were not different in their hurt feelings ratings.

\subsection{Discussion}

Experiment 2 proves that the failure to deliver the truth convincingly is an emotional experience that involves hurt feelings. No gender effects were found for hurt feelings.

The following research question is whether these results hold when participants tell the truth to judges who presume deception and participants are subsequently informed that they failed to convince the judges of their truthful communications? The next experiment was planned to answer this question.

\section{Experiment 3: Effects of Feedback and Presumption of Deception on the Overestimated Truth Telling Ability}

The purpose of Experiment 3 was to put the overestimated assessment of the truth-telling ability to a test in a

Table 3. Means (and SDs) of hurt feelings ratings when the communication fails to convince.

\begin{tabular}{|c|c|c|c|c|c|c|c|c|c|}
\hline & Detect Lie & Tell Lie & Trust Others & Tell Truth & Truths & Lies & Detect & Tell & Total \\
\hline \multicolumn{10}{|l|}{ Males } \\
\hline Mean & 67.3 & 41.3 & 72.5 & 81.8 & 77.1 & 54.3 & 69.9 & 61.5 & 65.7 \\
\hline SD & 28.4 & 31.5 & 21.7 & 19.7 & 15.8 & 22.3 & 17.2 & 18.3 & 12.9 \\
\hline \multicolumn{10}{|l|}{ Females } \\
\hline Mean & 65.8 & 31.8 & 69.8 & 77.3 & 73.5 & 48.8 & 67.8 & 54.5 & 61.1 \\
\hline SD & 27.5 & 29.0 & 27.5 & 22.0 & 21.5 & 21.2 & 22.7 & 19.7 & 16.9 \\
\hline \multicolumn{10}{|c|}{ Across Gender } \\
\hline Mean & 66.5 & 36.5 & 71.1 & 79.5 & 75.3 & 51.5 & 68.8 & 58.0 & 63.4 \\
\hline SD & 27.8 & 30.4 & 24.6 & 20.9 & 18.8 & 21.8 & 20.0 & 19.2 & 15.1 \\
\hline
\end{tabular}

Note: Higher scores indicate higher ratings of hurt feelings. 
truth-detection task where deceptive statements are more accessible than true statements (simulating presumption of deception). It was expected that truthful participants operating in this context would lower the assessment of their truth-telling ability. Another goal of the present study was to examine the effect of a confirming feedback indicating that truth tellers were believed, and a challenging feedback that indicates that truth-tellers performed worse than they may have expected. It was hypothesized that in the case of a confirming feedback the illusion of transparency is reinforced and becomes more salient to the participant. It is expected that a positive feedback further increases expectations of success in delivering the truths convincingly. A challenging feedback interferes with the illusion of transparency and encourages participants to reconsider their assessments of their ability to deliver the truths convincingly. It also reduces their expectations that their truths will be believed to a more realistic level.

\subsection{Method}

\subsubsection{Participants}

A total of 60 (8 male and 52 female) undergraduate students participated in the experiment for course credit. Their mean age was 22.4 years ( $S D=3.0$ ). Participants were promised a reward of 40 NIS (about $10 \$$ ) for an outstanding performance as truth tellers.

\subsubsection{Procedure}

Twelve groups of five participants each were asked to participate in a truth-telling experiment. Participants were first asked to self-assess their own lie-detection, lie-telling, truth-telling and trusting abilities, relative to others, on a scale ranging from 0 (much worse than others) through 100 (much better than others), with 50 (as good as others) serving as the middle point.

Then, a modified version of Gilovich et al.'s (1998) experiment was applied. Two female experimenters conducted the experiment. They first confirmed that the session participants were not acquainted with one another. Then, they seated the participants in a circle. Each participant completed a questionnaire containing 30 items relating to biographical and personal data (e.g., "what was the name of the high school you attended?"; "what are your main fields of interest?”; "what is your birth order?”). The questionnaires were collected by Experimenter A, who selected several of the 30 items for the follow-up presentation.

Participants were next asked to introduce themselves to the other group members, using their first name. Each participant received and wore a nametag with his/her first name on. Experimenter B explained that the purpose of the study was to investigate people's ability to be convincing in telling the truth. Participants were informed that their role is to be convincing while presenting one truthful and four deceptive short reports pertaining to the personal information they have provided. There were five rounds. In each, four participants were told to lie and one participant was instructed to tell the truth. The truth teller was unknown to the other participants. Each participant was designated as the truth-teller in one of the five rounds.

Participants were further instructed that their task was to detect the truth-teller in each round and to convince other participants of their own truths when they told the truth. In the remaining rounds, participants were asked to deliver a convincing lie and avoid detection of their lie by the other participants. Senders were asked clarifying questions by the receivers immediately after their presentation. Each receiver was allowed to ask one question each sender in each round. A bonus of 40 NIS (about 10\$) was promised to the most convincing truth-teller.

In each of the subsequent five rounds, Experimenter A handed each participant a card indicating the topic for presentation ("we will discuss now your fathers' occupation") and the participant's assigned role ("truth-teller" or "liar"). Participants presented their information according to their assigned topic and roles, in succession. Meanwhile, Experimenter A verified that participants followed the instructions, that is, the designated truthteller told the truth and the designated liars lied.

After each round, participants wrote their decision on separate cards. Truth-tellers were asked to estimate the number of participants who would believe their story. Answers ranged from none (0) to all (4). Participants were explicitly reminded that on average, one person out of four could be expected to believe their truth merely by guessing. Liars used their cards to write the name of the person who they believed was telling the truth. Experimenter B collected the cards. Meanwhile, Experimenter A prepared the next item and assigned new roles to the participants for the next round.

Participants in each of the 12 groups were randomly assigned to three feedback conditions, and received ei- 
ther confirming feedback, challenging feedback, or no feedback on their truth-telling performance. The number of participants in each feedback condition was counterbalanced across groups. After the first five rounds, a break of about 5 minutes was announced. Participants were informed that their performance would be evaluated during the break. Participants in the no-feedback condition proceeded to the next stage without receiving any feedback on their truth telling performance. Participants in the confirming feedback condition were handed a note "indicating" that their truthful story was believed by three of the four receivers, thereby, confirming that they performed better than chance. Participant in the challenging feedback condition were informed that their truth was believed by only one person (similar to the expected performance by chance) and was disbelieved by the three remaining participants.

To examine the feedback effects on participants' subsequent predictions, participants took part in an additional session of five rounds. The procedure was similar to that described for the first five rounds using different items of personal information. After the final round, participants were asked to rate again their lie-telling liedetecting, truth-telling and trusting abilities. At this stage, each participant disclosed the item about which they told the truth and the best truth-teller received the promised bonus. Finally, the experimenters conducted a short debriefing. The time of the experimental session was about one hour.

\subsection{Results}

The data of participants which was collected in each session may be confounded in the sense that the evolving inter-personal dynamics may have influenced subsequent assessments and predictions. It was therefore decided to aggregate data in the lowest level of independence (Kenny, 1996).

In the current study, the lowest level of independence is the level of the group. Therefore, scores were averaged for the three feedback groups at this level (e.g., when two participants in the same group were assigned to the same feedback condition, their scores were averaged and treated as a single unit).

\subsection{Self-Assessed Abilities to Tell and Detect Lies and Truths}

A $3 \times 2 \times 2 \times 2$ ANOVA with one between-subject factor, Feedback (the three feedback conditions) and three within subject factors, Time (before and after the feedback), Communication (to tell vs. to detect) and Sincerity (lies vs. truths), was conducted on the mean ability assessments (Table 4). A significant, $F_{(1,33)}=11.5, p=.002$, $\eta_{p}^{2}=.26$, main effect for Sincerity was obtained. Table 4 reveals that self-assessments of truth-related abilities were rated higher than self-assessments of lie-related abilities. All other main effects failed to reach the level of significance.

A significant, $F_{(1,33)}=5.0, p=.032, \quad \eta_{p}^{2}=.13$, Time $\times$ Sincerity interaction effect was obtained. A significant, $F_{(1,33)}=5.3, p=.028, \eta_{p}^{2}=.14$, Communication $\times$ Sincerity interaction effect, was also found. These interactions were further explained by the significant, $F_{(1,33)}=4.6, p=.04, \eta_{p}^{2}=.12$, Time $\times$ Sincerity $\times$ Communication interaction. The interaction shows that higher self-assessments were assigned to the truth telling

Table 4. Percent mean (and SDs) of the self-assessed truth/lie-related abilities before and after Experiment 3.

\begin{tabular}{|c|c|c|c|c|c|c|}
\hline & Detect Lies & Tell Lies & Trust Others & Tell Truths & Truths & Lies \\
\hline \multicolumn{7}{|l|}{ Before } \\
\hline Mean & 57.1 & 49.7 & 62.1 & 67.6 & 64.9 & 53.4 \\
\hline SD & 17.3 & 18.0 & 16.1 & 12.8 & 9.9 & 15.1 \\
\hline \multicolumn{7}{|l|}{ After } \\
\hline Mean & 53.4 & 54.6 & 58.8 & 61.6 & 60.2 & 54.0 \\
\hline SD & 15.9 & 18.1 & 12.6 & 16.2 & 11.3 & 13.9 \\
\hline \multicolumn{7}{|l|}{ Across } \\
\hline Mean & 55.3 & 52.2 & 60.4 & 64.6 & 62.5 & 53.7 \\
\hline SD & 14.6 & 14.6 & 12.7 & 12.2 & 9.2 & 12.5 \\
\hline
\end{tabular}

Note: Higher scores indicate higher ratings. 
ability in the beginning of the experiment than in the end of the session. This was clearly indicated by a paired sample t-test which was conducted on these means, $t_{(35)}=2.3, p=.03$. In comparison, the lie telling ability was assessed higher at the end of the experiment than in the beginning of the session. The interaction further shows that the ability to tell the truth was assessed higher than the ability to tell lies, both at the beginning, $t_{(35)}=4.9, p$ $<.001$, and at the end of the session, $t_{(35)}=2.2, p=.039$.

It is noteworthy that the analysis did not show any significant feedback effect. However, a closer inspection of the truth-related assessments reveal that both the truth-telling and the trusting abilities were assessed higher before the challenging feedback (Mean $=67.7, \mathrm{SD}=14.7$, and Mean $=60.0, \mathrm{SD}=14.6$, respectively) than after the feedback (Mean $=61.0, \mathrm{SD}=16.3$, and Mean $=54.6, \mathrm{SD}=13.7$, respectively). Paired sample t-tests which were conducted on these means revealed significant time differences, $t_{(11)}=2.4, p=.037$, and $t_{(11)}=2.3, p=.041$, respectively.

\subsection{Predicted and Actual Success in Truth Telling}

A $3 \times 2 \times 2$ ANOVA with one between-participants factor (Feedback) and two within-participant factors, Time (before the feedback, after the feedback) and Success (predicted vs. actual)—was conducted on the mean performance scores (Table 5).

A significant main effect, $F_{(1,33)}=39.6, p<.001, \eta_{p}^{2}=55.0$, for Success was obtained, indicating that the predicted success was much higher than the actual success. A marginally significant, $F_{(1,33)}=2.7, p=.08, \eta_{p}^{2}$ $=14.2$, Feedback $\times$ Time $\times$ Success interaction effect show a significant, $t_{(11)}=3.9, p=.002$, decline of the predicted success after the challenging feedback. There was no significant difference in the predicted success after the confirming feedback or when no feedback was introduced. As a result the predicted success after the second five rounds, remain significantly higher than the actual success in the confirming, $t_{(11)}=3.1, p=.011$, and in the no feedback, $t_{(11)}=4.2, p=.002$, conditions. In the challenging condition, the predicted success was significantly higher than the actual success before the feedback, $t_{(11)}=3.8, p=.003$, but not after the feedback, $t_{(11)}=1.2$.

\subsection{Discussion}

Experiment 3 put the truth-tellers to a test in a well-controlled situation. The experimental situation employed receivers who presumed senders' deception and senders who were motivated to deliver their truths convincingly and were confident of their ability to do so. In addition, two feedback conditions and one control condition were employed to explore the feedback effects on the ability assessment scores and on predicted success in convincing receivers of the senders' truth. Feedback either confirmed (positive feedback) or challenged (negative feedback) participants' truth-telling performance. Unexpectedly, feedback did not affect participants' subsequent self-assessed truth telling ability. However, the challenging feedback led to a subsequent decline in the predicted

Table 5. Means (and SDs) of predicted and actual detection of participants' truths before and after the feedback, in three false feedback conditions.

\begin{tabular}{ccccccccc}
\hline Feedback on & \multicolumn{2}{c}{ Confirming Feedback } & \multicolumn{2}{c}{ No Feedback } & \multicolumn{2}{c}{ Challenging Feedback } & \multicolumn{2}{c}{ Across Performance } \\
& Mean & SD & Mean & SD & Mean & SD & Mean & SD \\
\hline Predicted & & & & & & & & \\
Before & 2.38 & $(.48)$ & 2.25 & $(.72)$ & 2.69 & $(.66)$ & 2.44 & $(.64)$ \\
After & 2.21 & $(.84)$ & 2.45 & $(1.00)$ & 1.83 & $(1.03)$ & 2.16 & \\
Actual & & & & & & & \\
Before & 1.42 & $(.90)$ & 1.67 & $(1.11)$ & 1.50 & $(.88)$ & 1.53 & $(.95)$ \\
After & 1.21 & $(1.01)$ & 1.28 & $(.78)$ & 1.44 & $(.94)$ & 1.31 & $(.89)$ \\
Predicted & 2.29 & $(.46)$ & 2.35 & $(.71)$ & 2.26 & $(.78)$ & 2.30 & $(.65)$ \\
Actual & 1.31 & $(.70)$ & 1.47 & $(.61)$ & 1.47 & $(.64)$ & 1.42 & $(.64)$ \\
\hline
\end{tabular}

Note. The mean number of persons to be detected just by chance $=1$. 
success to deliver the truth. Confirming feedback showed a similar, yet more moderate effect. This means that the presumption of deception rather than the feedback was responsible for the decline of both the self-assessed truth telling ability and the prediction of success.

As in Experiment 1 the present sample is skewed and most of the participants were females. This dictates caution when interpreting the results. Although the few male participants were evenly assigned to the three feedback conditions, and no gender differences were found with respect to the reported hurt feelings when the truth is challenged (Experiment 2), possible gender differences may have affected the results.

To conclude, the results of the third experiment support the results of the first two experiments in showing how disbelieved truthful communications reduces truthful participants' confidence that their truth is evident to others.

\section{General Discussion}

The anticipated state of mind of disbelieved truthful people was the focus of the present study. Specifically, it was intended to explore: a) whether individuals tend to assess their ability to convince others in the truthfulness of their true messages higher than other people and extremely high irrespective of reference to other people; b) whether the highly rated truth-telling ability is associated with attributed importance; c) whether and to what extent people feel hurt when a truthful communication fails to convince; d) whether these results hold when they are put to a test in a truth-detection task where deceptive statements are more accessible than true statements (simulation of the presumption of deception), and where feedback indicates that truth-tellers performed worse than they may have expected (feedback of disbelief).

The present set of studies indicated that people consider truth-telling a highly important trait and tend to overrate their truth-telling ability. When their truths failed to convince they reported feeling hurt. When participants delivered their truths to recipients who presumed deception their self-assessments of the ability to tell the truth convincingly declined and their initial predictions about their success to convince others of their truthfulness dropped to a more realistic estimate. Most of these results are straightforward and intuitive. However, they are extremely important when they are put in the proper context.

The illusion of transparency (Gilovich et al., 1998) seems to play a major role in constructing the truth-tellers' state of mind. Under this illusion, truth-tellers assume that their truth is transparent to others and believe their truth to be more easily detected than it actually is. One way to examine this bias is to ask people about their beliefs. The present results showed a tendency towards a truth-telling bias, that is, people tend to overestimate their own truth-telling abilities. This was found with reference to other peoples' truth-telling ability (Experiment 3) and without such reference (Experiment 1). Critics may argue that participants intentionally over-rate their truthtelling ability for purposes of self-presentation with the intent of creating an impression of trustworthiness and credibility, while in practice they did not know precisely where they stand compared to others in their ability to deliver the truth convincingly. Williams and Gilovich (2008) indicated otherwise. They showed that people truly believe in their high self-assessments and take their estimates seriously enough to guide their choices.

The following question is whether the present results may teach us more about actual situations where truthful people might find themselves in. For example, confidence in truth-telling is especially important during job interviews. A successful employment interview is the outcome of the impression that the candidate owns the desired traits. Therefore, when there is no need to lie, truthful impression formation strategies and the perceived ability to convince others in employment interviews may increase candidates' prospects to become employed (Reinhard, Scharmach, \& Müller, 2013).

Of interest is the question how truthful people, who perceive themselves as being convincing truth tellers, will respond when they face hard-to-tell truths? Such hard-to-tell truths are common in situations where missed deadlines, excuses for absenteeism and performance evaluations have to be provided. Some people, who perceive themselves as being good at deceit, may provide a plausible but untrue excuse. However, the present study shows that many people tend to assess low their lie-telling ability and assess high their truth-telling ability. Such people may deliberate whether to tell the hard-to-tell truth as it is risking the consequences, or try and find an excuse which entails the risk that their lie might be detected (they believe they are poor liars after all) and impair their credibility.

Innocent suspects in the criminal interrogation offers an extreme example of the truth-tellers' dilemma. Here, the suspect must deliberate whether to tell the truth as it is with the risk that the story might not be sufficiently 
plausible and therefore may fail to convince the investigator, or to modify the story to enhance its plausibility which entails the risk that their lies might be detected and thus increase the investigators' suspicion.

Before we continue describing the interrogation situation and the relevancy of the present results to that situation, let us review the limitation of the current study. Note that we employed students as participants a sample which is not a representative of the criminal suspect populations. Furthermore, Experiments 1 and 3 used highly skewed samples where the majority of the participants were females while the majority of suspects interrogated in criminal interrogations are males. Finally, the present studies are low stake studies which are different in many respects from the actual high stakes interrogation situation. These limitations dictate extra caution when we try to learn from the present results about the actual interrogation situation.

However, people have confidence in their ability to deliver their truth convincingly. This is repeatedly observed among various groups of participants, not only female students. Thus, it was observed among male prisoners (Elaad, 2009) who better represent the suspect population than students. It was also observed among police interrogators and laypersons (Elaad, 2009) as well as students (Elaad, 2011). It is safe to conclude that the confidence in the truth telling ability is a general belief and can be attributed to truthful suspects in the interrogation as well.

There is no reason to believe that the association between the highly assessed truth telling ability and its attributed importance does not exist among criminal suspects. Until proved otherwise, we may speculate that innocent suspects consider their truth telling ability very important.

If people highly appreciate their truth-telling ability, any failure to deliver the truths convincingly might result in hurt feelings and in emotional reactions. This was clearly indicated in Experiment 2. Furthermore, male and female participants did not differ in the hurt feelings they reported. It may be suggested that in the interrogation, truthful suspects who are challenged with disbelief would feel similar feelings. Some may lose patience and actively resist the false allegations.

Experiment 3 indicated that presumption of deception is associated with losing confidence in the truth-telling ability. Similarly, presumption of guilt is typical to the interrogation, and truthful suspects are expected to lose confidence in their ability to convince. When challenged with disbelief the process of losing confidence accelerates and this may end in despair and low prospects for success.

Now let us describe an interrogation situation of innocent suspects for which the present results may be relevant. Note that this is not necessarily the only possible situation, and even not the most common one. The present results may imply that innocent suspects who are accused of a crime they did not commit are confident of their ability to convince the interrogators of their innocence. Some innocent suspects may be driven by the belief in a just world where everyone gets what one deserves (Granhag \& Hartwig, 2008). Others may rely on the illusion of transparency and trust their investigators' ability to discern their truth (Gilovich et al., 1998). Trust leads falsely accused suspects to feel that there is no need to convince the investigators of their innocence (Granhag \& Hartwig, 2008). Therefore, they make no special effort to prepare for the interrogation and provide a sound story to back up their truth. This state of mind drives them to cooperate with the police, wave their right to silence and agree to be interrogated based on the assumption that they have nothing to hide (Kassin \& Norwick, 2004). Furthermore, the importance some innocent participants attribute to the truth in general and to their ability to tell the truth convincingly (Experiment 1), may make them volunteer true information that oppose their own interest.

Such trust is not justified because in many cases interrogators are captivated by the investigator bias (Meissner \& Kassin, 2002) and hold preconceptions about the suspects' guilt. The tendency of police investigators to overestimate their ability to detect lies (Elaad, 2003, 2009), helps to sustain the investigator bias.

In many interrogation situations, suspects tell both truths and lies, and investigators who presume guilt look for these lies. To catch a suspect in a lie, investigators tend to rely on inconsistencies between consecutive statements (Granhag \& Stromwall, 2002), between statements from several suspects (Granhag, Stromwall, \& Jonsson, 2003), and between statements and physical evidence (Park et al., 2002). Investigators tend to point out such inconsistencies and contradictions and use them to strengthen their suspicion. As a result, innocent suspects' confidence in their ability to deliver their truth convincingly collapses. Many become frustrated, hurt, impatient, distressed and nervous, and lower their expectations of being able to convince their investigators. All their appearance indicates guilt. Vrij and Granhag (2007, cited in Vrij, 2008), gathered and reviewed a number of police manuals and reported that these manuals always point at patterns of nervousness as signs of deception. For example, Rabon (1992, cited in Vrij, 2008) pointed at the restless behavior of the suspect, Zulawski and Wicklan- 
der (1993, cited in Vrij, 2008) suggested to look for jerky behavior, Gordon and Fleisher (2002, cited in Vrij, 2008) emphasized restless foot and leg movements, Inbau, Reid, Buckley and Jayne (2001, cited in Vrij, 2008), pointed at frequent posture changes to which police interrogators should attend.

The investigators, who are now convinced that the suspect is guilty, adopt even more aggressive techniques and put more pressure on the innocent suspect. Kassin (2005) noted that at this stage, investigators tend to ignore conflicting evidence. Tension between interrogators and innocent suspects increases, further enhancing investigators' suspicions and aggressive interrogation. Ultimately, the prospects for innocent suspects to confess to a crime they did not commit increase.

However, some people under interrogation manage to resist this psychological pressure and avoid subscribing to the belief that their truths are not convincing. It may be suggested that such resistance may be the result of past experience as suspects. Specifically, in the past these individuals received feedback that strengthened their perception of their own ability to tell truths convincingly. In any case, people may be trained to feel less vulnerable to investigators strategy to reduce their self-confidence, by a continuous positive feedback on their truthtelling performance. This would suggest that training may prepare innocent suspects to stand firm behind their truths when confronting an aggressive investigator. To corroborate these suggestions, future research is advised to study lie-telling and truth-telling assessments after their communication failed to convince, of individuals with experience as suspects, such as prisoners.

\section{Conclusions and Future Research}

The present results emphasize the prominence of the perceived truth telling ability among other perceived lie/truth abilities. The perceived ability to convince when telling the truth is important in protecting existing relationship, pursuing new relationships, ensuring product or service quality, and many other social contacts. Therefore, it is so hurting when the truth is disbelieved. However, research on various aspects of the perceived truth telling ability is in its creation. Future research is advised to study different contexts in which the perceived ability to tell the truth is being challenged. For example, the degree of familiarity between the truth teller and his or her interacting partner, stress situations, how attractiveness of the sender and the receiver of a truthful communication affects the interaction, how respected/disrespected appearance of both affect the communication, and many other context variables. Future studies should also address effects of demographic and cultural variables such as age groups, gender, religiosity, education, economical status, and professional expertise on the perceived ability to deliver a truthful communication convincingly.

\section{References}

Bond, C. F., \& DePaulo, B. M. (2006). Accuracy of Deception Judgments. Personality and Social Psychology Review, 10, 214-234. http://dx.doi.org/10.1207/s15327957pspr1003_2

Buller, D. B., \& Burgoon, J. K. (1996). Interpersonal Deception Theory. Communication Theory, 3, $203-242$. http://dx.doi.org/10.1111/j.1468-2885.1996.tb00127.x

DePaulo, B. M., Lindsay, J. J., Malone, B. E., Muhlenbruck, L., Charlton, K., \& Cooper, H. (2003). Cues to Deception. Psychological Bulletin, 129, 74-118. http://dx.doi.org/10.1037/0033-2909.129.1.74

Ekman, P., \& O’Sullivan, M. (1991).Who Can Catch a Liar? American Psychologist, 46, 913-920. http://dx.doi.org/10.1037/0003-066X.46.9.913

Elaad, E. (2003). Effects of Feedback on the Overestimated Capacity to Detect Lies and the Underestimated Ability to Tell Lies. Applied Cognitive Psychology, 17, 349-363. http://dx.doi.org/10.1002/acp.871

Elaad, E. (2009). Lie-Detection Biases among Male Police Investigators, Prisoners, and Laypersons. Psychological Reports, 105, 1047-1056. http://dx.doi.org/10.2466/PR0.105.F.1047-1056

Elaad, E. (2011). Effects of Feedback on Self-Assessed and Actual Abilities to Tell Lies. In: A. E. Hasselm (Ed.), Crime: Causes, Types and Victims (pp. 155-166). Hauppauge, NY: Nova Science Publishers.

Elaad, E., Lavy, S., Cohenca, D., Berholz, E., Thee, P., \& Ben-Gigi, Y. (2012). Lies, Truths, and Attachment Orientations in Late Adolescence. Personality and Individual Differences, 52, 670-673. http://dx.doi.org/10.1016/j.paid.2011.12.018

Gilovich, T., Savitsky, K., \& Medvec, V. (1998). The Illusion of Transparency: Biased Assessments of Others’ Ability to Read One’s Emotional States. Journal of Personality and Social Psychology, 75, 332-346. http://dx.doi.org/10.1037/0022-3514.75.2.332

Granhag, P. A., \& Hartwig, M. (2008). A New Theoretical Perspective on Deception Detection: On the Psychology of In- 
strumental Mind-Reading. Psychology, Crime \& Law, 14, 189-200. http://dx.doi.org/10.1080/10683160701645181

Granhag, P. A., \& Stromwall, L. A. (2002). Repeated Interrogations: Verbal and Nonverbal Cues to Deception. Applied Cognitive Psychology, 16, 243-257. http://dx.doi.org/10.1002/acp.784

Granhag, P. A., Stromwall, L. A., \& Jonsson, A. C. (2003). Partners in Crime: How Liars in Collusion Betray Themselves. Journal of Applied Social Psychology, 33, 848-867. http://dx.doi.org/10.1111/j.1559-1816.2003.tb01928.x

Kaplar, M. E., \& Gordon, A. K. (2004). The Enigma of Altruistic Lying: Perspective Differences in What Motivates and Justifies Lie Telling within Romantic Relationships. Personal Relationships, 11, 489-507.

http://dx.doi.org/10.1111/j.1475-6811.2004.00094.x

Kassin, S. M. (2005). On the Psychology of Confessions. American Psychologist, 60, 215-228. http://dx.doi.org/10.1037/0003-066X.60.3.215

Kassin, S. M., \& Norwick, R. J. (2004). Why People Waive Their Miranda Rights: The Power of Innocence. Law and Human Behavior, 28, 211-221. http://dx.doi.org/10.1023/B:LAHU.0000022323.74584.f5

Kassin, S. M., Bogart, D., \& Kerner, J. (2012). Confessions That Corrupt: Evidence from the DNA Exoneration Case Files. Psychological Science, 23, 41-45. http://dx.doi.org/10.1177/0956797611422918

Kenny, D. A. (1996). The Design and Analysis of Social-Interaction Research. Annual Review of Psychology, 47, 59-86. http://dx.doi.org/10.1146/annurev.psych.47.1.59

Meissner, C. A., \& Kassin, S. M. (2002). “He’s Guilty!”: Investigator bias in Judgments of Truth and Deception. Law and Human Behavior, 26, 469-480. http://dx.doi.org/10.1023/A:1020278620751

Miller, G. R., \& Stiff, J. B. (1993). Deceptive Communication. Newbury Park, CA: Sage.

Park, H. S., Levine, T. R., McCornack, S. A., Morrison, K., \& Ferrara, M. (2002). How People Really Detect Lies. Communication Monographs, 69, 144-157. http://dx.doi.org/10.1080/714041710

Reinhard, M. A., Scharmach, M., \& Müller, P. (2013). It’s Not What You Are, It’s What You Know: Experience, Beliefs, and the Detection of Deception in Employment Interviews. Journal of Applied Social Psychology, 43, 467-479. http://dx.doi.org/10.1111/j.1559-1816.2013.01011.x

Tversky, A., \& Kahneman, D. (1974). Judgment under Uncertainty: Heuristics and Biases. Science, 185, 1124-1131. http://dx.doi.org/10.1126/science.185.4157.1124

Vrij, A. (2008). Detecting Lies and Deceit: Pitfalls and Opportunities (2nd ed.). Chichester: Wiley.

Williams, E. F., \& Gilovich, T. (2008). Do People Really Believe They Are above Average? Journal of Experimental Social Psychology, 44, 1121-1128. http://dx.doi.org/10.1016/j.jesp.2008.01.002 